\title{
Artistic Style and Performance Skill of Aria Hundreds of Happy and Beautiful Girls
}

\author{
Hui Zhang \\ Department of Art, Ankang University, Ankang 725000, China
}

Keywords: Vivaldi's opera; Hundreds of Happy and Beautiful Girls; Artistic style; Performance skills

\begin{abstract}
The opera creation of Vivaldi was one of the outstanding representatives of baroque music style, and is still an inseparable teaching material in the vocal music learning. Taking the mezzo-soprano aria Hundreds of Happy and Beautiful Girls in Vivaldi's opera Loyal Fairy as an example, it is attempted to discuss the artistic characteristics and performance skills of Vivaldi's opera, and it is concluded that the performers should both comply with the classic regulations, and master and perform the artistic style that Vivaldi's opera is full of the passion of force, has energetic and strongly growing vitality, so as to deduce the figure image in the opera with the spirit of times.
\end{abstract}

\section{Introduction}

Baroque style is one of the important parts of European artistic and social civilization, which benefited the music exploration, drawing and literature at that time with its mature and rich human spiritual connotation, as well as the meticulous and beautiful progressivism in literature atmosphere and the clear naturalism artistic charm, especially it had a profound and deep penetration to the important works opera performance. The "baroque" period was a great period of opera birth, and also an important period of vocal music art development. The vocal music art in this period advocated the "sweet, soft and love-filling" sound. Antonio Vivaldi was an important opera composer in "baroque" period, who spent his whole life in the heyday of the European baroque art, his opera works were like her music arts, with extremely excellent and comprehensive artistic property, and always with the tactful and elegant vocal music beauty, colorful and bright picture beauty and deep and meticulous artistic beauty. In this paper, his work opera mezzo-soprano aria I will leave, I will fly, I will whoop is analyzed, which is beneficial to master the baroque opera style and improve the performance skills.

\section{Plot introduction and structural analysis of aria Hundreds of Happy and Beautiful Girls}

\section{Plot introduction}

The mezzo-soprano aria Hundreds of Happy and Beautiful Girls is from Vivaldi's opera Loyal Fairy, also called Loyal Fairy Fid and Fid Ninfa, which told the story of the female god and the love story among the female god, sheepherder and pirate. The lyric connects them very ambitiously, but the decoded stories are puzzling. There is no complicated plot in this opera, but only the excellent explanation understood by Vivaldi. La Fida Ninfa has even tone, simple rhythm, with the rhythm similar to Alleluja and many components of coloratura and virtuosity. The mezzo-soprano aria Hundreds of Happy and Beautiful Girls is an aria telling the story of a girl, the good friend of a fairy, expressing the feeling of being urgent to see the beloved sheepherder.

\section{Structural analysis}

The mezzo-soprano aria Hundreds of Happy and Beautiful Girls is of D major, allegro, 2/4 beat, with simple and exquisite structure and consistent phrase length. It has a prudent and considerable layout in tone, with free and rich syntactic behavior, tight and magnificent music line, representing the style of baroque music. The whole aria is an ABA ternary form with representation. The whole music is dominated by quaver, semiquaver, syncopation, front and rear 16-rhythm type, and the whole music is of grading and jumping sound type, expressing the urgent, happy and pleasant feelings of hundreds of girls to welcome hundred of sheepherders. Particularly, the frequent use of 
quaver and semiquaver in minors 21-29 and minors 46-52 express the feelings of being urgent to see the lovers to the extreme, and bring a happy, harmonic and relaxed atmosphere.

\section{Vivaldi's music style and its influence on Hundreds of Happy and Beautiful Girls}

\section{Vivaldi's music style}

The vocal music and opera works of Vivaldi are full of rich and complex behavior everyone. A poet who once contacted with Vivaldi described him as a figure shaped by many quite different materials; although he was weak and often ill, he was energetic like a man of disposition; he was easy to lose temper, but he could keep calm immediately; he was devoted to the worldly and unnecessary businesses, but soon he worshiped the holy god; he was stubborn in temper, but if necessary, it was easy to discuss with him; he was a mysterious believer, but was willing to bear the guilty happiness in the world; if the problem involved in his personal interest, he was absolutely not foolish to deal with his personal affairs. All these were so harmonious with his music. In his works, either the lofty and tragic feeling of religion, warmness of human heart, deep thought and daily life, the abstract and specific illusion were integrated into a whole. In his vocal music and opera works, there was the song of the common people, poetic expression from inner mind and the happy aria etc.

From the opera works of Vivaldi, we can hear his music gift, active rhythm, warm rhythm, the luxurious sound and music them were surprising and comparable, it can be said that these opera works fully reflect the characteristics of the baroque music, becoming the miniature of the same kind of works. Accumulating the profound tradition of humanism since the Renaissance of Italy, so Vivaldi's opera works did not have more miracles, but were full of pure atmosphere, just like the sunshine of the Korean Peninsula, giving people warmness and happiness. There was no sadness and anger, but only quietness and happiness in his pen. Some people say " Vivaldi's music sounds like a song." Indeed, generally Vivaldi's works had similar melody and tone, and the shadow of the famous work Four Seasons also can be found in the opera. People listened to Bach for his sufferings, Brahms' music was for these in love, while Vivaldi's music was those happy. Even the opera aria expressing anger or sadness would show strong work enthusiasm. I think Vivaldi's characteristics represent an endless and strong upward vitality. Italy was the place where the baroque music was originated and grew, while the opera and vocal music works of Vivaldi were also recognized the baroque excellence in the classical vocal music works.

\section{Influence of Vivaldi's music style on Hundreds of Happy and Beautiful Girls}

Vivaldi was not only a composer, but also a versatile violinist, and even after acting as many years' copier of many famous composers, he still maintained his due temper. There was no low-sound music in his opera, but only Foerana dance music and light dance etc., all were accompanied with violin, regardless of the lyric, tone and stage environment, he was sure to make the whole music occasionally happy and sad from the start to end. All opera arias of Vivaldi were " da capo arias", with ABA structure. His opera arias have extremely strong instrument property, and usually the grading and jumping sounds would be used, the flexible conversion of which cast the biggest characteristics of Vivaldi's vocal music works, and we can enjoy the extremely strong instrument property, and this is also a difference from other composers. He took vocal music as an instrument in the whole band, making vocal music and each instrument dialogue and developed, with accompanying of instrumental music in the opera Hundreds of Happy and Beautiful Girls.

\section{Performance skills and times spirit of aria Hundreds of Happy and Beautiful Girls}

\section{Performance skills}

Repeated short phrases of fixed rhythm

The repeated short phrase of fixed rhythm means that the always fixed sound type is always performed repeatedly, during the performance of short phrases, what is needed is the rapid inspiration and slow expiration, and during performance, it is required to control the volume of performance, so as to increase the flexibility of sound. The performance volume should not be too high, but should be 
gentle and flexible, and it is required to maintain the coherence between phrases and also keep the accurate rhythm. For example:
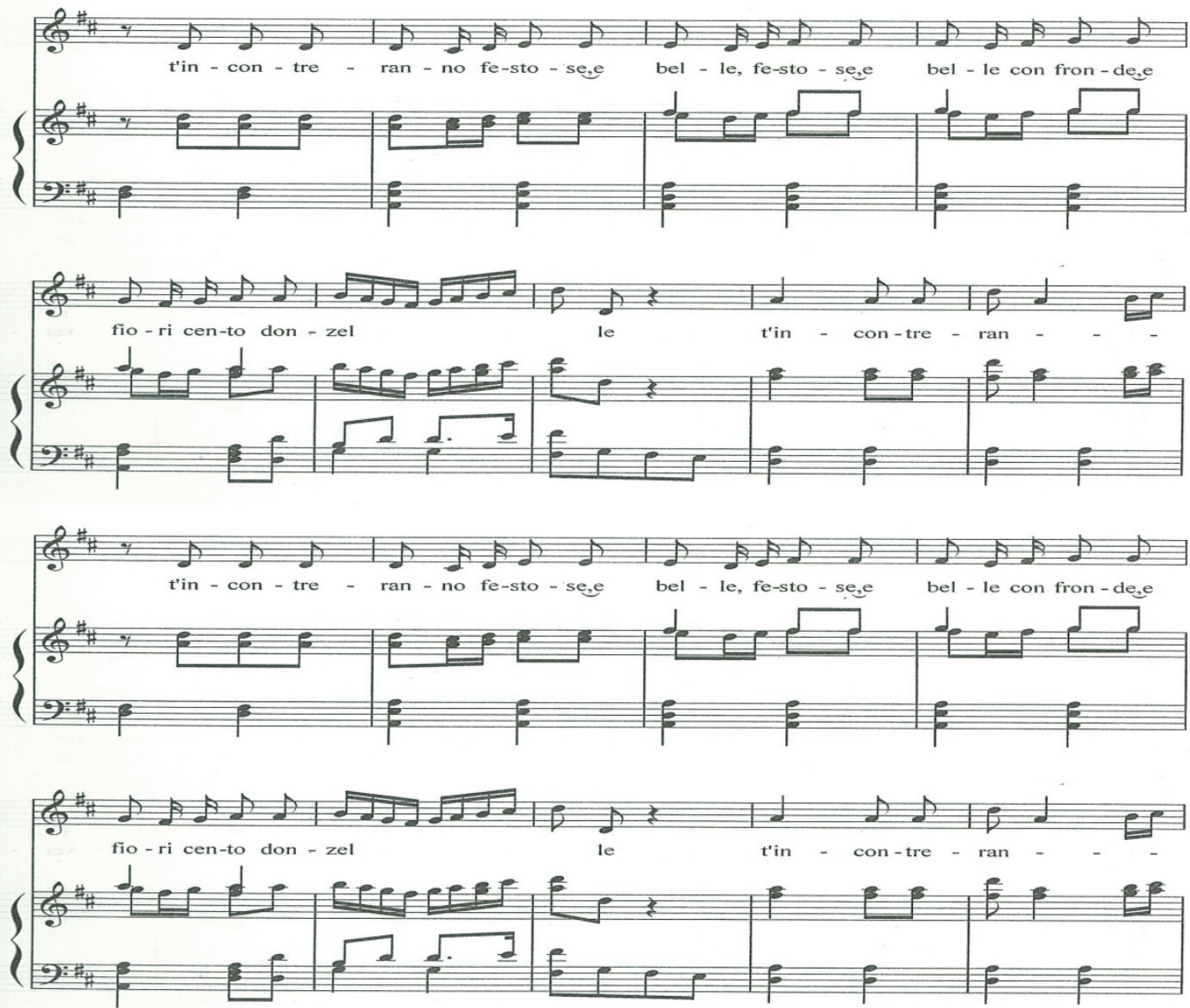

It can be seem from the above score that the short phrases performed were almost of quaver and semiquaver types, with a very rapid performance speed, clear and strong sense of grain. In the usual practice, it is required to add some auxiliary practices more, for example, use the abdomen muscle for the practice of "dog breathing”, so as to increase the flexibility of breath. When the practice reaches a certain extent, it is possible to life the musculus risorius for practice with "dog breathing", only the point of head voice resonance and cooperation of abdomen muscle can reach a relatively complete coordinative performance. Meanwhile, when performing such type of sound, it is required to blend feelings, and the feelings of performance should not be influenced because of fixed type of sound. The breath should not be too rigid, and it is required to breath cyclically, so as to ensure the relaxed and smooth performance.

Performance skills of coloratura phrase

The German coloratura is the meticulous and exquisite decoration of rhythm, with sharp and rapid lyric, luxurious paragraphs and vibrato like speaking, and according to the initial music or impromptu singing, this is a high-difficulty challenge for the performers. When performing the coloratura phrases, it is required to control the breath and keep the vocal cavity and throat in a relaxed and natural state. During performance, it is required to pay attention to the coherence of breath and ensure that each sound is clear and has a strong sense of grain. For example: 

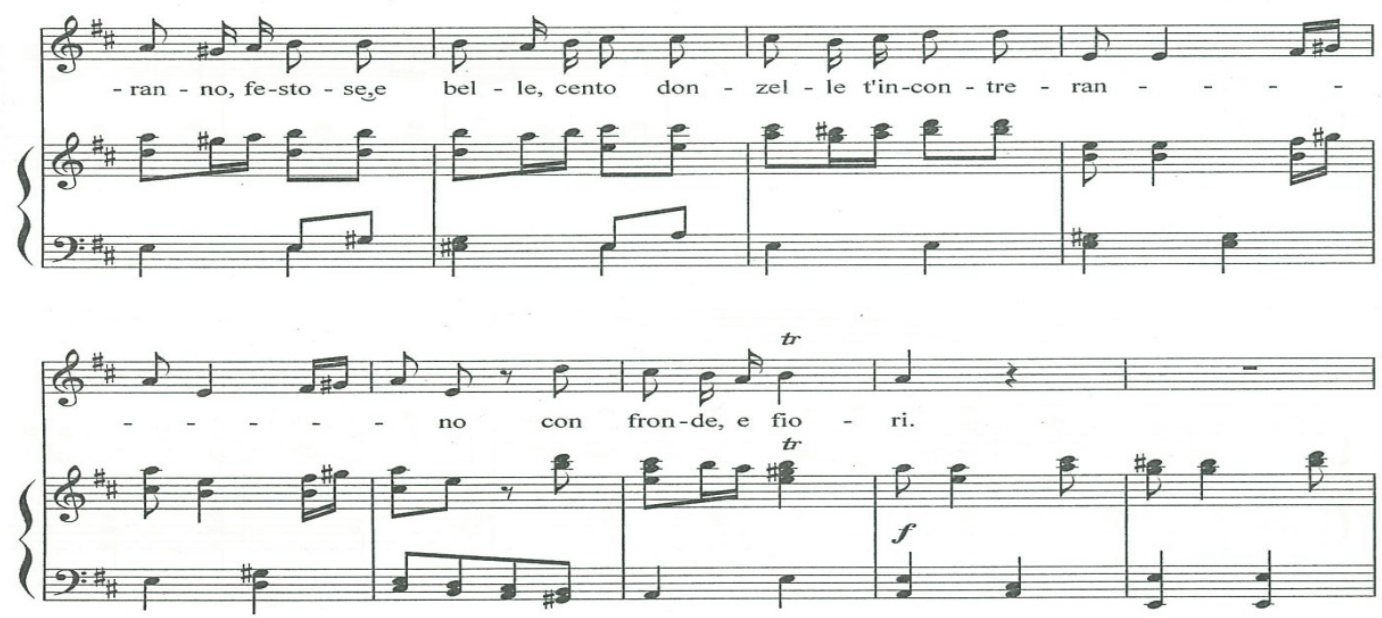

When practicing the coloratura phrase in the score, it is required to be slow and sing the high pitch accurately, and then add the sense of "high breathing".

Ensure the smooth, fluent and coherent performance. During performance, it is better not to take a breath, otherwise, the contents and hearing of the whole coloratura will be influenced, thus reducing the performance difficulty. To sing each sound clearly with elasticity, it is not only required to sing the sound accurately, but what's more important is to add the performance of stress, so as to enhance the performance in the mood of music.

Spirit of times

The western opera blends the comprehensive artistic form of drawing, color, decoration, clothes and other elements, with a rich and wonderful visual aesthetics to the overall feelings. Prevailing in the Italian baroque art, the increasing of drama, poem and music in opera was a relatively common technique to enhance the connotation of the literature works. The distinctive and rich artistic atmosphere is also easy to improve the performance of the whole opera work. Vivaldi was also accustomed to relying on this classic to independently treat, process, adapt and deduce the opera creation method. He was a composer and performer with very high aesthetic style and cultivation, and also had striking ability in the comprehensive creation ability of opera works. In his opera works, he paid more attention to the interaction between vocal music and image, the simple singing of songs, luxurious lyrics and the ordered paragraph and exquisite connotation all constructed vivid, active and bright images.

Unlike Handel of the same period, no one regarded Vivaldi as the first-class composer in the field of vocal music works. But on the other hand, he had extremely excellent orchestration manifesting the baroque style. His vocal music works were highly difficult, through the absorption of singing experience and continuous research and analysis, some instruments except piano are naturally required to perform the aria of Vivaldi. I have referred to a lot of materials, and found that in the foreign professional music departments, the indoor music has always been an inseparable learning content for those majoring in bel canto and musical performance. Their graduation examinations consist of solo concert, repertoire concert and indoor music. Indoor music originally referred to the music similar to "family type" performed in the room, and later, it was expanded to the music performed in a small place, including various instrument solos and vocal music performance. During the performance of this aria, the violin accompanying was added on the basis of the original piano accompanying, forming a form similar to the indoor vocal music. This does not only increase the stylistic characteristics of the works themselves, but also more conforms to and is appropriate to the times background of baroque. The vocal music courses carried in the form of indoor music accompanying will surely be rich and colorful, and such novel form can expand the teaching contents, enrich the students' performance style, enhance the students' perception and performance to music and require the students to have higher musical quality and professional performance ability. 
Meanwhile, we should see that in the $21^{\text {st }}$ century, the music culture in the world is increasingly diversified, and it is far from being enough to only devote to the research and performance of Mozart and Verdi etc. in the classic and romantic opera vocal music works. Deeply learning and researching the broad vocal music works of the "baroque" period including Vivaldi cannot only expand our horizon, enrich the number of vocal music in China, but can also deepen our understanding of development history of opera, expand the communication channel of Chinese music culture and foreign culture and also will have a beneficial influence on further expanding the vocal music creation and widening the research thought. After experiencing Verdi's opera full of patriotic and heroic spirit, the emerging " bravura singing" makes too many domestic vocal music performers infatuated with the glorious and metallic sound. However, the "soft, sweet and love sound" required for the vocal music works during the "baroque" period is not concerned enough. Brining the initial vocal requirement of bel canto is not only a review to the initial creation of bel canto art, but also will have a great enlightenment for the Chinese vocal music teachers to pay attention to the diversity in vocal music training according to the different conditions of students.

\section{Conclusion}

Vivaldi's opera was an artistic treasure in the baroque civilization, although it has been forgotten for a long time, its shinning light cannot be concealed. His opera works contained and released the beauty of vocal music, image and art, making people excited. The opera works of Vivaldi also play a benign effect to the creation and deduction of modern opera. It is of vital to scientifically understand and deeply recognize the property characteristics of baroque opera art and accurately and comprehensively analyze and understand the connotation of opera works of Antonio Vivaldi, so as to effectively promote the coordinative, rapid and long-term development of the modern opera creation.

\section{References}

[1] Written by Roland de Cande (French), translated by Jiang Lili, Photo Biography of Vivaldi, Beijing: China Renmin University Press, August 2005

[2] Written by Pam Brown, translated by Qi Yanqiang, Vivaldi, Beijing: Foreign Language Press, 1998

[3] Liu Xincong, Liu Zhengfu, European Vocal Music History, Beijing: China Youth Publishing House, 1999

[4] Translated by Jia Diran, reviewed by Zhou Xiaoyan, 26 Alto Arias of Vivaldi, Anhui: Anhui Literature and Art Publishing House, March 2011

[5] Guan Jinyi Western Vocal Music History, Beijing: People’s Music Publishing House, March 2007

[6] Zhao Bomei, Art of Signing, Shanghai: Shanghai Music Publishing House, April 2006 